\title{
THE USE OF MULTI-TEMPORAL SENTINEL SATELLITES IN THE ANALYSIS OF LAND COVER/LAND USE CHANGES CAUSED BY THE NUCLEAR POWER PLANT CONSTRUCTION
}

\author{
E. Çolak ${ }^{*}$, M. Chandra ${ }^{2}$, F. Sunar ${ }^{3}$ \\ ${ }^{1}$ ITU, Civil Engineering Faculty, Geomatics Engineering Graduate Program, 80626 Maslak Istanbul, Turkey \\ colakem@itu.edu.tr \\ ${ }^{2}$ Chemnitz University of Technology, Germany \\ madhu.chandra@etit.tu-chemnitz.de
}

${ }^{3}$ ITU, Civil Engineering Faculty, Geomatics Engineering Department, 80626 Maslak Istanbul, Turkey fsunar@itu.edu.tr

KEY WORDS: Multi-temporal Data, Change Detection, Nuclear Power Plant, Sentinel $1 \& 2$.

\begin{abstract}
:
Turkey, due to increased demand for energy has made plans for nuclear power generation since 1970. Sinop Nuclear Power Plant, which will be built on Sinop İnceburun peninsula at the Black Sea coast of Turkey, is one of the three different nuclear power plants planned to be built in Turkey. The Sinop Nuclear Power Plant consist of four different reactors. The construction of the first unit is expected to be completed by 2023 , and the fourth unit is planned to be activated by 2028 . On the other hand, the construction of the nuclear power plant will alter the land use at the actual plant site and its surroundings and hence may cause significant environmental changes. As an indicator, more than 650000 trees have been cut so far for the construction of nuclear power plant, and this can adversely affect the ecological balances of the region by endangering habitats and creating ecological damages. The aim of this study is to analyse the land use/land cover changes (LULC) in the forestry-dominated areas due to the construction of nuclear power plants using the multi-temporal Synthetic Aperture Radar (SAR) and optical satellite images. For this purpose, different change detection methods such as SAR intensity image differencing, supervised image classification method (Support Vector Machine algorithm) were applied to Sentinel 1 satellite image datasets (2016-2019) to evaluate the annual changes due to construction. In addition, a correlation analysis was performed between the canopy structure and vegetation biomass using Sentinel 2 NDVI dataset (2016-2019) and calibrated Sentinel 1 backscatter values. Furthermore, using the Google Earth Engine (GEE), the Landsat 8 NDVI time series of the affected forest area, generated at 8 -day intervals, was used to validate changes in vegetation.
\end{abstract}

\section{INTRODUCTION}

Nuclear energy, used to produce electricity, is one of the most controversial alternative energy source on the market due to its advantages and disadvantages. The main reason for this is that the nuclear safety issue has become a global focus, especially in the wake of accidents such as the Fukushima nuclear plant explosion in Japan in 2011. Today, despite the slowdown caused by some major accidents, nuclear power plants continue to be built and there are around 450 commercial nuclear power reactors operating in 31 countries with combined capacity of about 400 GWe.

Although nuclear power production in Western and Central Europe has declined, because of the increasing environmental awareness and lessons learned from major accidents, nuclear power plants have still become a preferred source of electricity for many countries because they are reliable, affordable, sustainable and accessible. As shown in Figure 1, nuclear production in Asia and Eastern Europe and Russia has an increasing trend in 2017 (World Nuclear Association, 2018).

Although the diversification of Turkey's energy resources, existing primary energy sources are inadequate to meet demand. Therefore, due to increased demand for energy, Turkey has made plans for nuclear power generation since 1970. At present, there is no nuclear power plant in operation in Turkey, however, is planning to install three nuclear power plants, including 12 nuclear reactor units by 2030 .

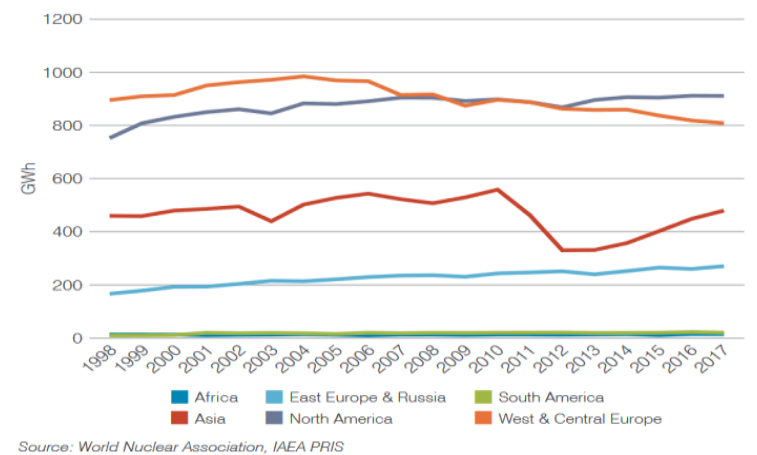

Figure 1. Regional nuclear power generation (World Nuclear Association, 2018).

Since Turkey is geographically located in highly active earthquake-prone regions, therefore, there is a need for higher safety requirements from the construction to the operation phases, based on new techniques, standardization and quality systems.

However, there is opposition and a strong antinuclear movement all over Turkey due to three nuclear power plants installation plans, especially for the one in the Black Sea province of Sinop, since this region has been heavily affected by radioactive fallout since the Chernobyl nuclear accident in 1986. On the other hand, nature conservation zones close to the region; e.g. Hamsilos National Park, which has many plant and animal species and fertile land, will be adversely affected. Besides, it is foreseen that 
fisheries will be affected negatively, since Sinop Nuclear Power plant's cooling water will be supplied from the Black Sea $(28$ million cubic meters per day), which provides $10 \%$ of the total fish consumed in Turkey.

As recently announced, the Japanese-funded Sinop nuclear power plant project was stopped due to a negative feasibility study report and cost analysis. Although it is currently halted, assessment of environmental changes during the nuclear plant site construction is essential, both in terms of monitoring the negative potential environmental impacts (e.g. air pollution, biodiversity loss, genetic contamination, loss of landscape /aesthetic degradation, soil contamination, etc.) as well as to produce reliable/relevant data and time series to feed safety assessments, traceability and protection. In this context, today space technologies, including remote sensing, provide tools for gathering information on land use/land cover (e.g. vegetation quality and quantity) and can provide a practical approach for mapping the environmental changes that occur.

In this study, the analysis of land use/land cover changes (LULC) and the effects of nuclear power plant construction in the area dominated by forests were performed using multi-temporal radar and optical Sentinel $1 \& 2$ satellite images. The results were associated with the canopy structure and vegetation biomass using Sentinel 2 NDVI dataset (2016-2019) and calibrated Sentinel 1 backscatter values; and verified using Landsat 8 NDVI time series produced by Google Earth Engine (GEE).

\section{STUDY AREA}

The Sinop Nuclear Power Plant was a planned nuclear plant located on İnceburun peninsula on the Black Sea province of Sinop, in an area where $99 \%$ of the land is forest (Figure 2). The Sinop Nuclear Power Plant is designed to have a 4,480-megawatt capacity of electricity generation with four reactors, each with a 1,120-megawatt capacity. It will be the country's second nuclear power plant after the projected Akkuyu nuclear power plant on the Mediterranean coast.

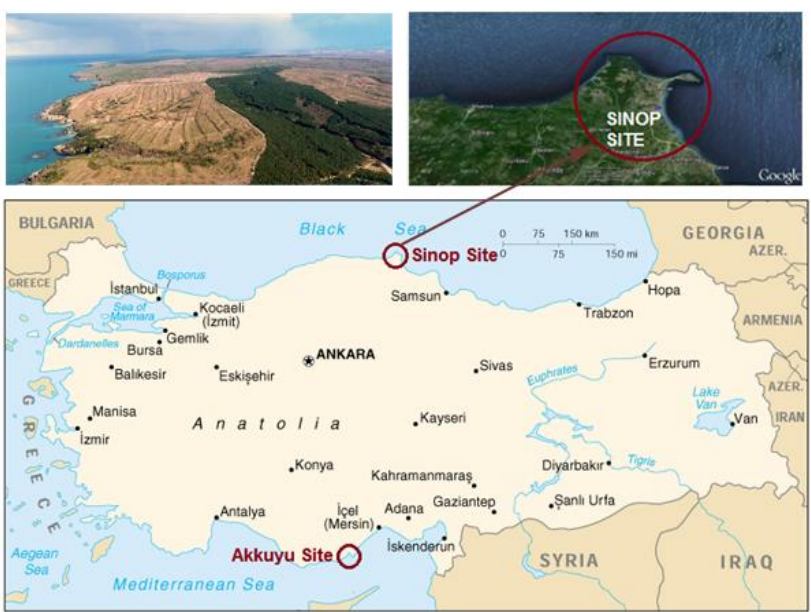

Figure 2. The map and images of the Sinop nuclear power plant.

The area of 10.1 square kilometres allocated for the nuclear power plant is close to nature protection zones; i.e. adjacent to Bozburun Wildlife Development Area; $3.1 \mathrm{~km}$ from Hamsilos Nature Park that is the only fjord of the Black Sea, $4.9 \mathrm{~km}$ from Aksaz-Karagöl Wetland and $4.2 \mathrm{~km}$ from Sarıum Nature Reserve (Figure 3). Since the agreement was signed, more than 650 thousand trees in the site area have been cut (i.e. almost $20 \%$ of the forested area has been deforested) for the feasibility work regardless of environmental costs/consequences they may bring about, i.e. posing a threat to society by endangering their habitats and creating ecological damage. The approval of the environmental impact assessment report for the project is expected this year.

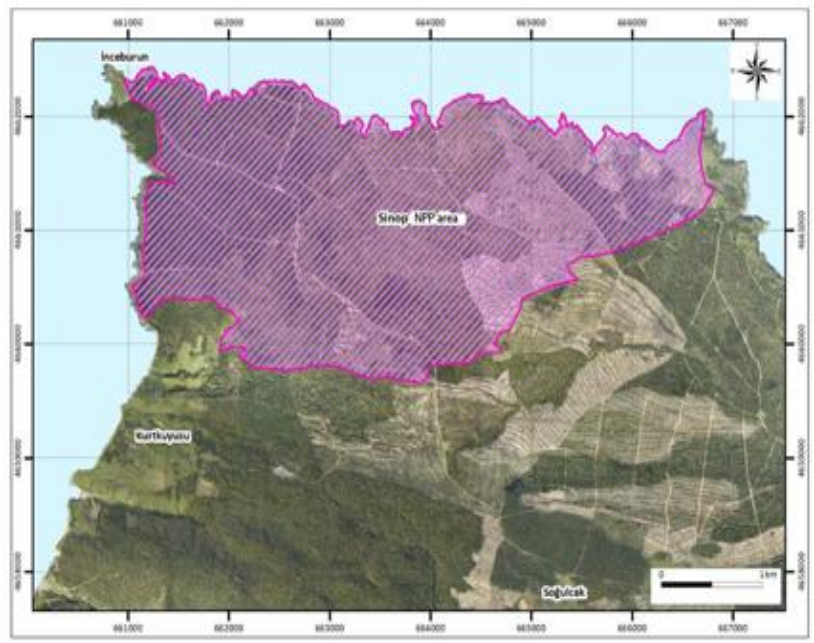

Figure 3. Sinop nuclear power plant project area (Sinop NGS projesi, 2017).

\section{DATA COLLECTION}

Multi-temporal Sentinel 1A images (dated June 3, 2016 and June 18, 2019) and Sentinel 2A images (dated June 18, 2016 and June $3,2019)$ were used in the analysis. Sentinel $1 \mathrm{~A}$ includes a SAR instrument operating in band $\mathrm{C}(3.75-7.5 \mathrm{~cm})$ and L1 GRD (Ground Range Distance) level, according to IW mode with the polarizations (VH) and (VV) was used (Table 1)(ESA-Sentinel, 2018).

Table 1. The characteristics of the Sentinel 1A data (ESA-Sentinel 2018).

\begin{tabular}{|c|c|c|c|c|}
\hline \multirow{2}{*}{$\begin{array}{c}\text { Acquisition } \\
\text { mode }\end{array}$} & $\begin{array}{c}\text { Product } \\
\text { type }\end{array}$ & $\begin{array}{c}\text { Resolution } \\
\text { Range } x \\
\text { Azimuth }(\mathrm{m})\end{array}$ & $\begin{array}{c}\text { Number } \\
\text { of looks }\end{array}$ & Polarization \\
\hline \multirow{2}{*}{ IW } & GRD & $10 \times 10$ & $5 \times 1$ & VH \\
\cline { 3 - 4 } & $40 \times 40$ & $22 \times 5$ & VV \\
\hline
\end{tabular}

For Sentinel 2A, the bands; 3 (Red) and 8 (NIR) which have 10 $\mathrm{m}$ spatial resolution were used to produce vegetation biomass data.

\section{METHODOLOGY \& APPLICATION}

In order to evaluate the results of forest destruction quantitatively and qualitatively, different image processing steps such as spectral vegetation indexes and classification were applied as shown in the flow chart (Figure 4). 


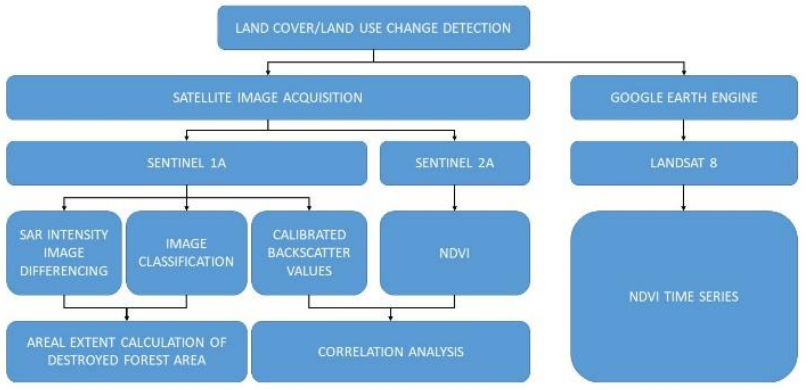

Figure 4. The process flow chart of the study. As a first step, "speckle", which is inherent in SAR images and known as the "salt and pepper (noise)" effect, is minimized by using the "Lee" filter ( 3 x 3 kernel size) to allow for easy interpretation of the image content.

\subsection{SAR Intensity Image Differencing}

Log ratio (LR) is the most common SAR intensity change detection method. It can turn the multiplicative noise into the additive noise, which it can decrease the intrinsic noise partially and reflect the change type in the difference map (Cui et al., 2017). It is represented with the following equation.

$d_{L R}=\log \frac{X}{Y}=\log X-\log Y$

Where $X$ and $Y$ are the multi-temporal SAR intensity images.

\subsection{Image Classification}

For assigning land cover classes to pixels, image classification method known as the most common image processing step is applied to multiband satellite data. In this study, Support Vector Machines (SVM) algorithm, efficient statistical classification method that determines how to define the boundary line (hyperplane) that can best distinguish two or more classes from each other, was used. The way the boundary line is defined depends on the training data used for the classification and the characteristics of the classes to be considered.

\subsection{SAR Calibration}

The purpose of SAR calibration is to provide images in which the pixel values can be directly related to the radar backscatter in the scene. Hence, Digital Numbers (DN) are converted to backscatter values using Equation 2.

$\sigma_{(d B)}^{0}=10 \times \log _{10} D N$

where $\sigma_{(d B)}^{0}$ is the backscattering coefficient and DN is the digital number.

\subsection{Spectral Vegetation Indexes}

Various spectral indices have been developed for qualitative and quantitative evaluation of the vegetation biomass using spectral measurements (Teillet et al., 1997). Normalized Difference Vegetation Index (NDVI) is the most widely used vegetation index because it is a measure of photosynthetic activity, vegetation greenness and condition (Fraser et al. 2000). Hence, NDVI was used for the immediate assessment of the canopy biomass before and after forest cut.

\subsection{Google Earth Engine (GEE) NDVI Time Series}

Google Earth Engine (GEE) is a cloud computing platform for planetary-scale environmental data analysis that can determine important parameters (i.e. NDVI and LST) from satellite image datasets. In addition, it visualizes the data and plots it in time series graphs (Chen et al., 2017). Hence, in this study, GEE is used to produce NDVI time series and verify the findings.

\section{RESULTS}

First, a SAR intensity image differencing method was applied to both Sentinel 1A images to detect the changes in the forest area. Figure 5 shows the change map produced.

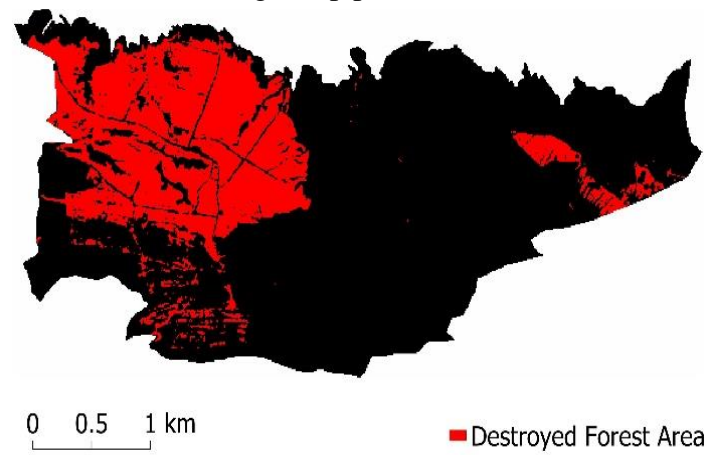

Figure 5. Change map of the study area.

As a result, the destroyed forest areas were calculated as 248.14 ha with the SAR intensity image differencing.

For the supervised classification, the SVM classification method were performed (Figure 6). The Sentinel 1A satellite image obtained at June 3, 2016 was classified into 4 major classes which are sea, coastline, bare soil, and forest area (Figure 6a); on the other hand, Sentinel 1A image obtained at June 16, 2019 was classified into 5 major classes which are sea, coastline, bare soil, forest area, and destroyed forest area (Figure 6b).
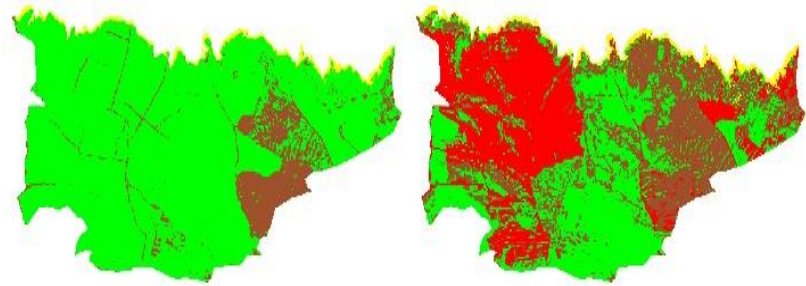

$$
\begin{array}{ccccc}
0,51 \mathrm{~km} & \begin{array}{c}
\text { Coast line } \\
\text { m Bare Soil }
\end{array} & 0 & 0,5 & 1 \mathrm{~km}
\end{array}
$$

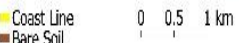$$
\text { a }
$$

Figure 6. Sentinel 1A SVM classification results.

(a) 2016 (b) 2019.

After the classification process, the accuracy assessment of SVM classification results were performed. The overall accuracies were calculated as $93 \%$ and $94 \%$ for June 3, 2016 and June 16, 2019, respectively. Destroyed forest areas was calculated as 268.09 ha by the SVM classification using Sentinel 1A 2019 data.

CORINE (Coordination of Information on the Environment) is LULC data produced by computer-assisted visual interpretation methods based on satellite imagery. To validate the findings, the CORINE LULC maps, done by Turkey Ministry of Agriculture and Forestry were used. Figure 7 shows the comparison of the two SAR processing results with the CORINE LULC (forest change between 2012 and 2018) data in the study area. 


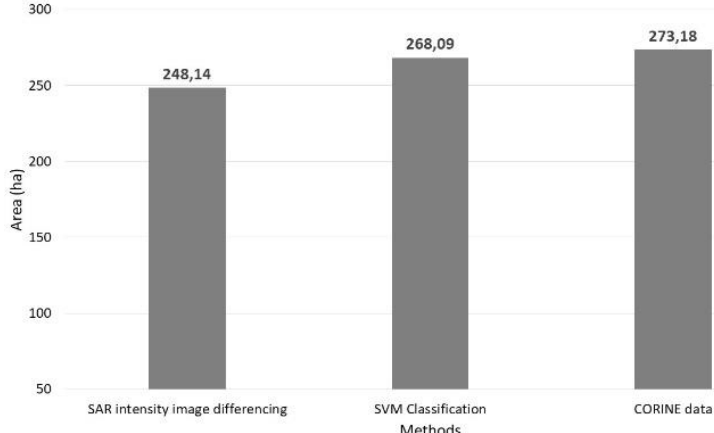

Figure 7. Comparison of the areal extents of the forest destruction mapped by different methods. (a) SAR intensity image differencing (b) SVM Classification (c) CORINE LULC data.

When the roots of the trees planted and cut in the area allocated to the Sinop nuclear power plant project are examined, it is stated that the trees are planted with 2 meters apart. Since sub-forest products and forest products are means of income by local people, $2 \mathrm{~m} \times 2 \mathrm{~m}$ spacing $(2,500$ trees per hectare) is generally regarded as the optimum in terms of cost and return (Coed Cymru, 2017). Consequently, it can be said that approximately 620000 to 670000 trees were cut down in the study area between the years 2016 and 2019. This is in line with the number of 650000 trees cut so far for the construction of the nuclear power plant claimed by environmentalists and civil protection organizations.

The NDVI images generated for both dates are given in Figure 8 and a profile is marked red in the affected forest area for subsequent analysis.

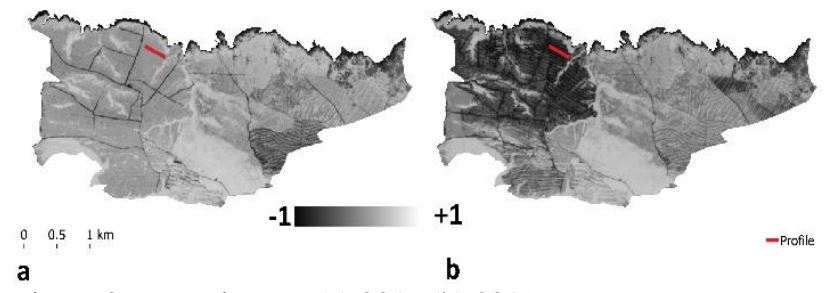

Figure 8. NDVI images (a) 2016 (b) 2019.

Spectral profiles for the marked profile were derived from Sentinel 2A NDVI dataset (2016-2019) and calibrated Sentinel $1 \mathrm{~A}$ images (Figure 9). As expected, there is a decline in NDVI and $\mathrm{dB}$ values in 2019 .

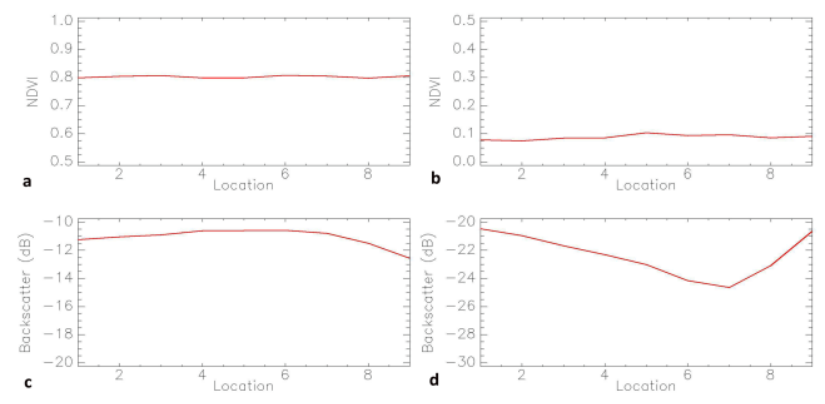

Figure 9. Spectral profiles of the profile marked in red. (a) 2016 NDVI (b) 2019 NDVI (c) 2016 backscatter (d) 2019 backscatter.

In addition, a correlation analysis between the canopy structure and vegetation biomass using Sentinel 2 NDVI dataset (20162019) and calibrated Sentinel 1 backscatter values were performed. As a result, the correlation coefficients between 2016
NDVI - SAR backscatter values and 2019 NDVI - SAR backscatter values were found as $\mathrm{R}=0.68$ and $\mathrm{R}=0.81$, respectively (Figure 10).
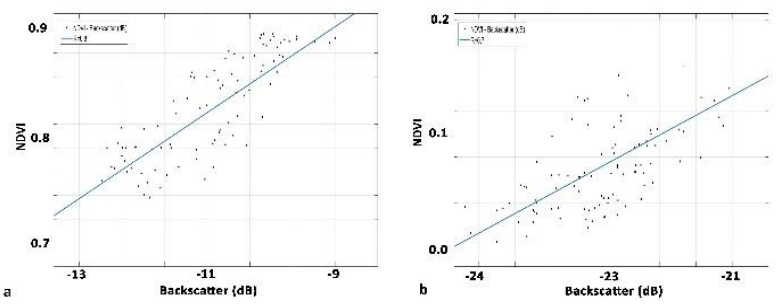

Figure 10. Correlation analysis between NDVI and calibrated SAR backscatter values. (a) 2016 (b) 2019.

Landsat 8 NDVI time series of the affected forest area, obtained at 8-day intervals, was produced using GEE to demonstrate vegetation biomass changes between 19 March 2013 and 17 June 2019 (Figure 11)

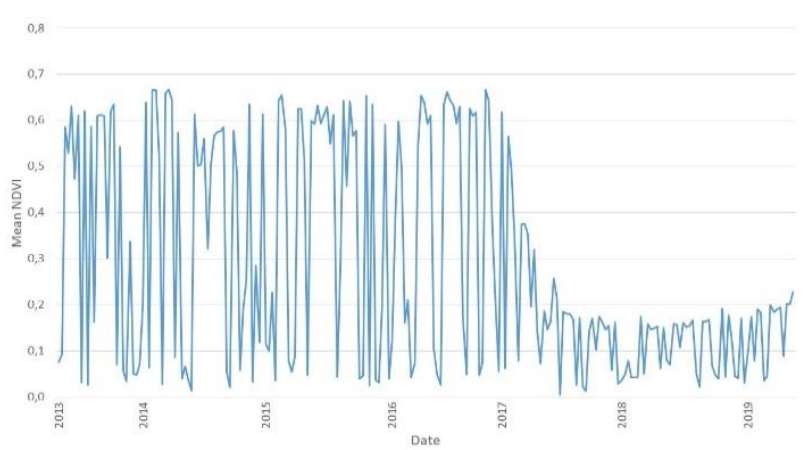

Figure 11. Landsat 8 NDVI time series of the affected forest area generated by using GEE.

As can be seen in Figure 9, NDVI values until April 15, 2017 show almost the same trend in the project area. However, the decline in NDVI time series is evident between April 15, 2017 and June 2019.

\section{CONCLUSION}

In recent years, Turkey has put forward energy strategies to promote nuclear power to meet the growing demand of national economy and social development. On the other hand, feasibility studies on the environmental costs/consequences they may incur should be done carefully, i.e. without posing a threat to society by endangering their habitats and creating ecological damages.

Today, complementary optical and radar Sentinel images are very helpful for accurate land use/land cover change mapping. In this study, the efficiency of the Sentinel $1 \mathrm{~A}$ and $2 \mathrm{~A}$ satellite images used to detect the changes occurred in the forest areas in Sinop, İnceburun peninsula at the Black Sea coast of Turkey was evaluated. The results of SAR intensity image differencing showed that 248.14 ha forest area was destroyed; on the other hand, SVM classification of 2019 SAR image demonstrated that 268.09 ha forest area was destructed. These results were in line with the number of 650000 trees cut so far for the construction of the nuclear power plant claimed by environmentalists/civil protection organizations; and CORINE LULC data.

A correlation analysis done between the canopy structure and biomass change using optical Sentinel 2 NDVI dataset (20162019) and calibrated Sentinel 1 SAR backscatter values gave that the correlation coefficient between 2016 NDVI - SAR backscatter values and 2019 NDVI - SAR backscatter values 
were $\mathrm{R}=0.68$ and $\mathrm{R}=0.81$, respectively. Correlations show that these two different datasets are synergistic in the assessment of vegetation changes. Furthermore, the Google Earth Engine platform approach has been found to be very efficient in assessing long-term change using NDVI time series of forests and their environment.

Finally, two main outcomes of this study can be outlined as: i) Sentinel $1 \mathrm{~A}$ and $2 \mathrm{~A}$ images provide different but complementary information about the degradation and loss of forests, although they have different spectral domains, ii) National nuclear power programs should be monitored and controlled using space technologies such as remote sensing data, taking great care to protect the environment.

\section{REFERENCES}

Chen, B., Xiao, X., Li, X., Pan, L., Doughty, R. 2017. A mangrove forest map of China in 2015: Analysis of time series Landsat 7/8 and Sentinel-1A imagery in Google Earth Engine cloud computing platform, ISPRS Journal of Photogrammetry and Remote Sensing, 131, 104-120.

https://doi.org/10.1016/j.isprsjprs.2017.07.011

Coed Cymru, 2017. A Basic Guide to Tree Planting. http://coed.cymru/images/user/Tree_Planting__Coed_Cymru_2 017.pdf

Cui, B., Zhang, Y., Yan, L., Cai, X. 2017. A SAR intensity images change detection method based on fusion difference detector and statistical properties, ISPRS Ann. Photogramm. Remote Sens. Spatial Inf. Sci., IV-2/W4, 439-443. https://doi.org/10.5194/isprs-annals-IV-2-W4-439-2017.

ESA-Sentinel, 2018.

https://sentinel.esa.int/web/sentinel/technical-guides/sentinel-1sar/products-algorithms/level-1-algorithms/products

Fraser, R. H., Li, Z., Cihlar, J., 2000. Hotspot and NDVI Differencing Synergy (HANDS): A New Technique for Burned Area Mapping over Boreal Forest, Remote Sensing of Environment, 74(3), 362-376.

https://doi.org/10.1016/S0034-4257(00)00078-X

Sinop NGS project, 2017. ENVY Energy and Environmental Investments Inc. (In Turkish), http://bianet.org/files/static/a/Sinop_NGS_CED_Basvuru_Dosy asi.pdf

Teillet, P. M., Stanez, K., William, D. J., 1997. Effects of spectral, spatial, and radiometric characteristics on remote sensing vegetation indices of forested regions. Remote Sensing of Environment, 61, 139-149.

https://doi.org/10.1016/S0034-4257(96)00248-9.

World Nuclear Association, 2018. World Nuclear Performance Report, August 2018, Report No. 2018/004. 